\title{
Information System resilience among Non-profits: Peak led collaboration as strategy for development
}

\author{
Anushke Guneratne \\ Department of Computing, \\ Macquarie University, \\ NSW 2109, Australia. \\ Email: anushke.guneratne@hdr.mq.edu.au
}

\section{Abstract}

Community legal centres (CLCs) are a special type of non-profit in Australia. These communities based organisations have operated in a considerably volatile funding environment. The funding limitations compounded by the relative size, and lightweight administration are a significant source of vulnerability which cannot be reduced by individual organisations. Their key strength is in community, engaging stakeholders and collaborating, which has helped CLCs continue functioning. This paper uses the development of a Customer Relationship Management system (CRM) by a peak body to investigate the notion that collaboration as a development strategy improves Information System development resilience. The strategic role of a peak body in relationship to its constituent organisations in the non-profit sector was found to be very important in creating system resilience.

Keywords: Non-profit, community legal centres, collaboration for resilience, Information System development, IT Strategy 


\section{Introduction}

Non-profit organisations (NPOs) come in many forms. It is quite common for these organisations to not have a formal administrative structure. This means that there is a lack of planning organisational resilience or longevity (Helmig et al. 2004). However, the many roles and service by NPOs are invaluable to society. Resilience planning in NPOs is a challenge due to their very nature, but should be a topic of considerable importance due to their role in society.

Community legal centres (CLCs) in Australia are a special type of NPO. Despite being NPOs they have been formalised through years of existence and donor/funder conditions (Giddings and Noone 2004). There are over 200 CLCs located throughout Australia (National Association of Community Legal Centres 2018), both in rural and urban contexts. As a whole, CLCs receive the majority of their funding from the government. Reliance on a single funding source is a source of vulnerability. An example of this vulnerability was seen in 2017, where the National Association for Community Legal Centres (NACLC) had to rally CLCs nationwide to reach out to their stakeholder base to improve Commonwealth budget commitments.

This paper investigates the impact of technological change and resilience in the context of funding changes at CLCs. More specifically, it highlights the importance of collaboration and the role of peak bodies in shaping strategy for resilience in the CLC sector. The first section of the paper provides the background in which the collaboration took place. This is followed by a section which provides definitions and existing literature which underpins the research. This will be followed by the methods, case study, discussion and conclusion.

\section{Background}

Community Legal Centres New South Wales (CLCNSW) is the peak body for CLCs in NSW, and has a membership of 38 centres. These 38 members comprise of 18 generalist CLCs, 18 specialist CLCs and 2 associate members. A generalist CLC covers many areas of law and serves within a particular region, city or suburb, while a specialist CLC focuses on law relating to a specific area. CLCs are an important part of the Australian legal system, providing "individual legal advice and assistance as well as law reform, test case litigation, referrals and community legal education activities aimed at addressing systemic problems" (p.258 Giddings and Noone). Funding for these non-profits has been primarily from state and federal government.

Funding arrangements vary and has seen changes over the years. Giddings and Noone (2004) note that government policy changes have resulted in funding changes for CLCs. Some such changes disregard the need for CLCs to be connected to the community, and having a voluntary service. The impact of these funding changes resulted in 109 CLCs having to turn away 169,513 people due to lack of resources and capacity (National Association of Community Legal Centres 2017b).

CLCs are known to underutilize Information Technology (IT), relying on external contractors to oversee the maintenance of their IT infrastructure, neglecting its strategic use. An internal report commissioned by CLCNSW, recommends that the peak body take up strategic servicing of sector wide IT needs. The report concluded that IT uptake in the sector is deficient, recommending better IT and Information System (IS) services are desirable for improving the sector. CLCNSW has undertaken deployment of a key identified infrastructure project; developing a Customer Relationship Management (CRM) system. In the absence of strategic input at individual CLCs, the lead taken by CLCNSW builds resilience. The case study uses the CRM development project to highlight sector wide collaboration serving as a strategy for building IS resilience.

\section{Literature review}

\subsection{Community organisations and the changing environment}

Voluntary sector organisations (VSO) such as CLCs provide services and information to disadvantaged segments of community. Te'eni and Young (2003) especially note that in the network economy, nonprofit organisations (NPO) are facing a broadening of their role in serving information needs. They base their assertion on the traditional excellence of NPOs in "facilitating transactions and creating relationships based on their information-related advantages (Te'eni and Young 2003) p.398)". CLCs are recorded to have arisen out of the need to correct the disadvantage of access to legal information, advice and representation (Giddings and Noone 2004). Giddings and Noone (2004) highlight that the establishment of CLCs was the result of a collective and activist approach which emphasised on social 
reform, rather than a case by case individual approach, and was distinctive in the involvement of nonlawyers approaching legal problems in the context of all the needs of the disadvantaged. CLCs therefore clearly represent the type of information providing NPOs which are important to society.

A key feature of the CLC sector is the use of volunteers in the delivery of services. National Association for Community Legal Centres (NACLC) reports that in the 2016/17 financial year 6,773 volunteers at 112 CLCs contributed nearly 890,000 hours (National Association of Community Legal Centres 2017b). Since this is only from about half the CLCs in Australia, it is quite likely that actual hours will be close to double that number. Giddings and Noone (2004) highlights the same factors where a core of salaried experienced legal workers are able to provide oversight to volunteers, composed mostly of lawyers and law students, as a core effective strength.

Despite the importance of CLCs in society, the nature of VSOs makes them susceptible to changes in their operations. One of the dominant challenges is the nature of the administration present in CLCs, which Helmig et al. (2004) mentions as "amateur (p. 102)". Identifying IT adoption Zorn et al. (2011)"suggest that NPOs adopting and using ICTs tended to be self-perceived leaders or those who [...] tended to have organizational decision makers with the expertise (p. 1)". In the case of CLCs Giddings and Noone (2004) note that a distinguishing characteristic of the early CLCs from their private counterparts was the lack of formal organisation and administrative systems. This is an understandable characteristic considering the size of CLCs, where having a comprehensive administrative team in a small organisation would consume a significant amount of resources (Crump and Peter 2013). This means CLCs would find IS resilience to be a challenge.

There clearly is an opportunity for technology to assist CLCs in delivering better targeted information to more people.

\subsection{Vulnerability sources for CLCs}

The nature of CLCs makes them inherently vulnerable to certain risks. The key vulnerability would be in funding, where a lack of long-term funding threatens operation and continuity. The second key vulnerability would be in weak administrative and management structures which can inhibit long term strategy.

Organisational resilience is achieved when an organisation is able to achieve its core objectives despite issues that crop up (Seville et al. 2006). However it should be noted that "organisations deal with uncertainties and unexpected events all the time [... ]Above a certain scale however, crisis events differ from day-to-day management, in that organisations have to operate out of their comfort zone" (Seville et al. 2006).CLCs are unique, that even though they are independent organisations, they operate as a larger entity when facing crises, exemplified by the sector wide campaigns in 2017 (National Association of Community Legal Centres 2017a). This indicates that there is a precedent in the CLC sector in facing crises in a united manner, and successfully reducing the threat. i.e. that collaboration is used to create resilience.

\subsection{NPO collaboration}

The CLC sector has a significant amount of collaboration. Guo and Acar (2005) researched into collaboration among non-profits, specifically looking into resource sufficiency, institutional factors and network effects and how it influenced collaboration. They found that formal collaboration takes place when organisations are older, receiving government funding, and has board linkages. The CLC sector bears all of the characteristics identified by Guo and Acar (2005).

The NSW Council of Social Services (NCOSS) studied possible models of access to shared services as well as possible challenges. A background paper prepared in 2008 identifies several drivers which are relevant to CLCs. It identifies government pressure to achieve economies of scale, increases in compliance costs, and skill and wage restrictions in hiring employees able to meet compliance needs as drivers for accessing shared services (NSW Council of Social Services 2008). Government "funding policies and practices [which] do not meet the full costs (administration/ infrastructure costs) of service delivery (NSW Council of Social Services 2008)" are already in place, which therefore restricts strategic capability (Giddings and Noone 2004). This provides incentive for strategic activity to take place in a shared manner.

Models of cooperation are also identified in the NCOSS (2008) paper. One of those identified is the peak body providing business centres. The benefits of this model are; the peak already having relationships with its constituent members, the peak body already providing services and therefore has a trust relationship established. 
Considering the interest of funding bodies in improving or expanding services without increasing funds, the economies of scale required can be achieved in collaboration. Crump and Peter (2013) in their study found that administrative overheads for smaller organisations can be around $10-15 \%$ higher than large organisations, and that such organisations were willing to pay up to $5 \%$ of their budget towards shared services(Crump and Peter 2013). This creates a niche for shared services.

\section{Methodology}

The case study focuses on the question of whether CLCs are keen on improving their ability to reach stakeholders, with the assumption that this will have an effect on improving donations and also campaigning capabilities. It will rely on data gathered from a survey conducted to ascertain the feasibility, support and scope of developing a CRM. The willingness of CLCs to contribute or participate will be treated as a proxy to answer the research question: are CLCs collaborating to increase technology resilience.

The survey received 48 responses from 32 organisations, out of a total 40 organisations. In instances where individual CLCs had multiple respondents, the respondent answers were combined manually to arrive at a consolidated response where needed.

The case study was formulated from the author's experience being part of both the technical and steering committees driving the project. Details of the project requirements and their formulation was gained from internal reports and discussions. The author is also employed in a technical capacity at a CLC, and has engaged in consulting across the CLC sector, which creates a general awareness of resourcing and other environmental factors common to the CLC sector.

\section{Boot strapped IS development in the CLC sector}

The CLCNSW project for a CRM for CLCs was funded by Legal Aid NSW through an administrative efficiencies grant. The case for developing this tool was drawn from a previous sector wide analysis (Table 1) which found a low overall technology maturity level in the sector. It was undertaken as collaboration between CLCNSW, the Tenants' Union of NSW (TUNSW), and NACLC. The TUNSW is a CLC, resourcing body for a state-wide tenants' advice and advocacy program (TAAP), and a registered training organisation and has a dedicated IT and resourcing team which has experience developing systems for the TAAP network. NACLC is the National body for CLCs, and has deployed a case management information system nationwide.

\begin{tabular}{|l|l|l|}
\hline \multicolumn{2}{|l|}{ Client and Stakeholder engagement } \\
\hline Supporter base & $\begin{array}{l}\text { There is a critical and urgent need } \\
\text { to find a solution to help CLCs } \\
\text { effectively manage their } \\
\text { supporters, and expand their } \\
\text { supporters and donors. }\end{array}$ & $\begin{array}{l}\text { CLCNSW is required to provide the Centre with } \\
\text { some recommended options for managing } \\
\text { supporters moving forward, as key stakeholders and } \\
\text { also a source of funding/donations. }\end{array}$ \\
\hline
\end{tabular}

Table 1: Recommendation for stakeholder engagement from sector wide IT audit (Community Legal Centres NSW 2016)

Engagement of the wider CLC sector took place in the form of surveys and regular updates as well as workshops which took place during a quarterly event. Many CLCs were interested and keen on using a CRM to effectively manage their stakeholders, volunteers and campaign activities.

The main collaboration partners formed two groups: a steering committee which would look at policy, needs and provide feedback on overall features and direction, and a smaller technical working group which was comprised of the IT staff in who would provide technological recommendations to the steering group. A notable point of discussion in both groups was the structuring of data on a shared system to maintain privacy and confidentiality while providing better collaboration.

Early on, there was significant interest using open source products, or a system fully owned by the sector to prevent commercial capture. There was keenness to avoid off-the-shelf systems. This was partly driven by the sector's experience with proprietary systems which did not receive updates for both security and compatibility, while also being difficult to customise or migrate away from.

The technical committee provided guidelines on infrastructure provisioning. The recommendations considered cost, security, on-going maintenance and scalability. Scalability was treated as non-critical as it would have a stable predictable user base. 


\subsection{Currently used tools}

One measure of technological maturity at a CLC would be to look at existing systems and processes in place to communicate with key stakeholders. The responses to the tools being used were diverse. Since the project was for developing a CRM that would integrate many communication functions, Table 2 summarises the responses indicating which of the CLCs already use a CRM.

\begin{tabular}{|l|l|}
\hline Question & CRM as response \\
\hline How does your CLC manage volunteers? & 2 \\
\hline How does your CLC manage and communicate with stakeholders? & 2 \\
\hline How does your CLC manage interactions with media outlets? & 0 \\
\hline
\end{tabular}

Table 2: Total number of CLCs indicating current use of a CRM

For systems to manage volunteers, 30 respondents from 17 CLCs indicated that they have no system in place. Similarly, for using an online donation collection system, 13 respondents indicated that there was no collection while 10 used a non-integrated free platform targeted at NPOs. Stakeholder communication was better as 12 indicated that they were using a popular commercial campaign mailing tool. However, there were still 8 respondents who indicated that it was a manual system.

The results of the survey are not surprising as it reflects the findings of the IT audit report which concluded low technology maturity. The report strongly recommended CLCNSW develop these services. The report and its findings most importantly indicated a strategy gap as responsible for holding the sector back from developing better technology.

\subsection{Stakeholder management using CRM}

The project selected CiviCRM an open source CRM. The tight budget available required selecting primary features which will appeal to many CLCs. Consideration was given to the possibility of 'seeding' the development through contributions to the open source community. Despite the interest in this option, factors such as uncertain timelines and budget constraints resulted in selecting an older version as the base system. The features considered were: discussion forums, e-learning, volunteer/stakeholder management tools, event management tools, online donations/payment gateway, and adaptable website templates. The final priority features decided upon were the volunteer/stakeholder management tools and adaptable website templates.

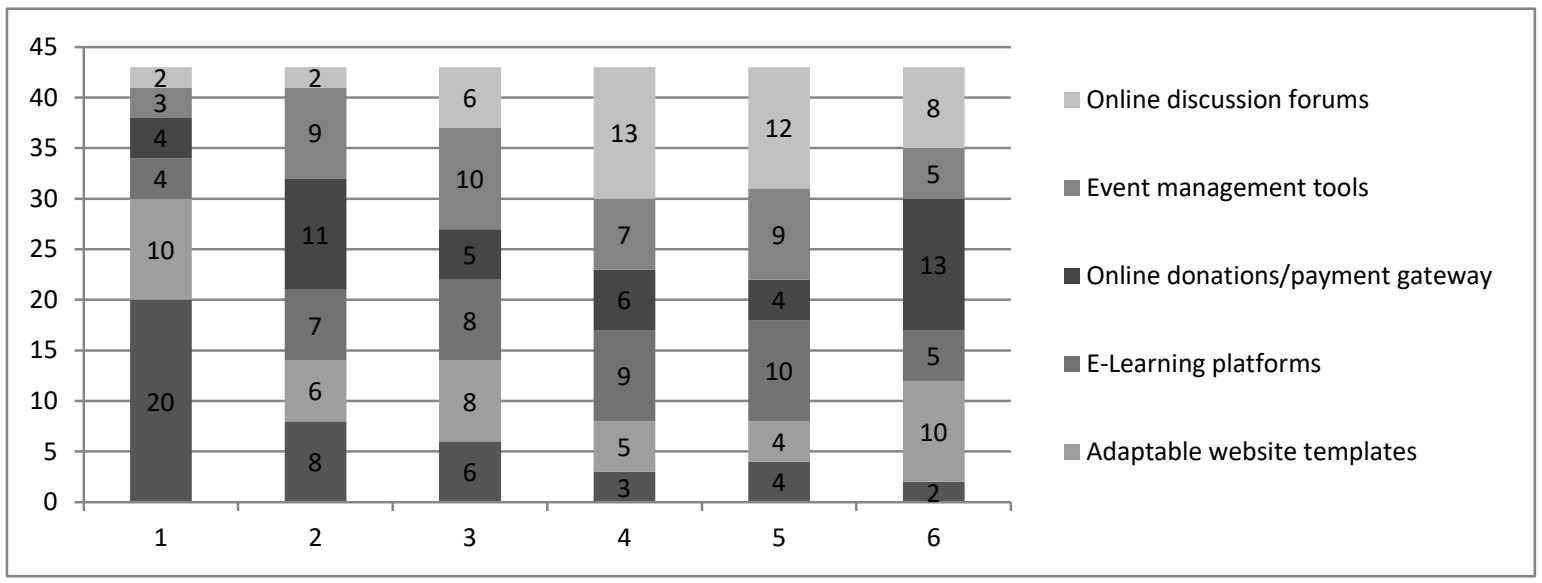

Figure 1: Feature ranking by user

The survey ranking the features provided insight into the diversity of the sector. There were only 43 responses from the 48 respondents for this question. The ranking of the features are summarised in Figure 1.

There was a lack of consensus on system priorities within a service, making it difficult to identify priorities. The survey did not expect CLCs to internally discuss and nominate their preferences. In instances where there were multiple respondents from the same CLC, a significant variation of priorities was seen. This diversity of responses from the sector and from within organisations point to the apparent strategic weakness which was identified common among VSOs. 
The strategic gap can be filled by providing the correct resources. Since CLCs are unable to individually resource a person capable of providing strategic guidance, the role would seem likely to fall upon a trusted party with proven capability. As such CLCNSW had the proper credentials and connections to champion the project, while also being able to draw on the support of organisations with relevant experience.

\subsection{Varied engagement levels}

When responses were aggregated, of the 32 responding CLCs 14 indicated that they were interested in only information about the project and participating in surveys. This could be due to lack of resources. This indicates internal barriers or resistance to participating in technology development, i.e. internal barriers to technological resilience.

\begin{tabular}{|l|l|}
\hline Answer for engagement willingness & No. of CLCs \\
\hline Keep me up to date with what's going on & 23 \\
\hline Happy to participate in online surveys & 21 \\
\hline Keen to be more closely involved in the design & 10 \\
\hline My CLC could pilot an aspect of the systems & 13 \\
\hline
\end{tabular}

Table 3: Willingness of engagement aspects indicated by each CLC

The levels of participation would likely be lower if the product was offered by a commercial entity, as has been the case for many CLCs. From anecdotal experience, a system which was offered as a cloud based solution resulted in lots failures during its operation over two years, primarily due to the lack of a technologically liaison. The service was not resilient in that aspect until a staff person was available to properly select a suitable system at a quarter of the cost, and has not had any major faults till now. Overall the willingness to collaborate shows the importance of trust relationships, and its role in forging a collaborative strategy.

\section{Discussion}

Due to funding limitations IT strategy is not prioritised, especially since the cost is believed to be not justified and better used in client services. My case study follows a peak organisations role in strategic IS development. Prior to the systems implementation, only manual or non-integrated systems were used. The project delivers an integrated solution, with the possibility for future extensions. Four CLCs are prepared to participate in the pilot stage. The on-going nature of the project is a drawback, as success or failure of implementation cannot be included for this study. However, CLCNSW as a peak body has managed to set up other strategic IT services, providing confidence that the CRM will also be successful.

One of the unique features of developing the CRM was the setting of project principles such as software selection requirements and the attempt to use sector based experience as much as possible. On-going financial requirements for the project are planned to be met through the monetization of completed components and other ICT services. This is possible due to the project being undertaken as part of a larger strategy allowing for a dedicated ICT staff position. This strategic approach and CLCNSWs past record indicates resilience in this collaborative approach. Furthermore, there was significant interest nationally with other peak bodies expressing their willingness to collaborate. This means that the developed system could have a larger user base creating financial viability for the IT services being offered.

Specifically, in regard to the project undertaken for NSW, the survey and sector level interest clearly indicates that while the project was needed, diversity can be a detriment to the project. In addition, the lack of resourcing both in general administrative and IT prevents a clear strategic direction for organisations individually and collectively. Such organisational diversity can only be moderated by a party that is trusted, which is why a state peak body such as CLCNSW has succeeded. The other smaller IT services which were offered as part of the larger program was quite successful.

Non-profit peak bodies have an important role to play in resourcing member organisations. In the development of the CRM, if each organisation had individually developed or contracted to develop a CRM or subscribed to an off the shelf service, it is quite likely that costs will be higher and the product unsatisfactory and fail to be resilient. In collaborating with the peak body, each organisation had an opportunity to participate while lowering overall costs for the entire sector. 


\section{Conclusion}

The CLC sector is not composed of homogenous organisations. It was identified that strategic IT capacity to develop a CRM individually was lacking. The study found that in the non-profit sector, organisations limited by funding and unable to access strategic decision making, collaborated through a peak body and resiliently developed a system. However future research will be required to identify the long term success or failure of this specific project, and what influences that outcome.

In NSW, CLCNSW using a one of grant developed a viable CRM which is being rolled out. The development process, collaboration and relationships indicate a high level of trust between resourcestrapped organisations. However, diversity among and within CLCs were brought to the surface, which makes the decision-making process complicated. Considering these dynamics, it is possible to outline recommendations which will help improve non-profit technological resilience.

Administrative overheads for employing dedicated staff for small organisations such as NPOs can be quite significant, while outsourcing can be inefficient. In light of this, it can be recommended that funders common to a sector can achieve better IS outcomes by creating a resourcing organisation or by better funding an existing peak body to provide relevant services and systems.

As a strategy resourcing through a peak body has many benefits. In this instance it lowered the cost of facing vulnerability. The collaboration created an overall improvement in technological resilience by creating a resource that was otherwise out of reach for small organisations. This indicates that nonprofit sector collaboration can be a resilience strategy, and also indicates that peak organisations have a bigger role in developing resilience and addressing risk for entire sectors composed of small organisations.

\section{References}

Community Legal Centres NSW. 2016. "Community Legal Centres NSW It Services Review Findings."

Crump, B., and Peter, R. 2013. "A Case for Non-Profit Organisations to Engage in the Use of Shared Computing Services," Electronic Journal of Information Systems Evaluation (16:4), p. 270.

Giddings, J., and Noone, M. A. 2004. "Australian Community Legal Centres Move into the TwentyFirst Century," International Journal of the Legal Profession (11:3), pp. 257-282.

Guo, C., and Acar, M. 2005. "Understanding Collaboration among Nonprofit Organizations: Combining Resource Dependency, Institutional, and Network Perspectives," Nonprofit and voluntary sector quarterly (34:3), pp. 340-361.

Helmig, B., Jegers, M., and Lapsley, I. 2004. "Challenges in Managing Nonprofit Organizations: A Research Overview," Voluntas: International Journal of Voluntary and Nonprofit Organizations (15:2), pp. 101-116.

National Association of Community Legal Centres. 2017a. "Annual Report 2016-2017." Retrieved 14/o6/2018, from http://www.naclc.org.au/resources/2017-10-30-NACLC-Annual-Reportfinal-web.pdf

National Association of Community Legal Centres. 2017b. "National Census of Community Legal Centres 2016 National Report." Retrieved 10/06/2018, from http://www.naclc.org.au/resources/NACLC\%20Census\%202016\%20National\%20Report\%20 -\%20FINAL.pdf

National Association of Community Legal Centres. 2018. "Find a CLC." Retrieved 14/o6/2018, from http://www.naclc.org.au/clc directory.php

NSW Council of Social Services. 2008. "Shared Services in the Ngo Sector Background Paper." from https://www.ncoss.org.au/sites/default/files/public/SharedServices_NGO.pdf

Seville, E., Brunsdon, D., Dantas, A., Le Masurier, J., Wilkinson, S., and Vargo, J. 2006. "Building Organisational Resilience: A New Zealand Approach," Resilient Organisations Research Programme. Disponível em: www. resorgs. org. $\mathrm{nz}$ ).

Te'eni, D., and Young, D. R. 2003. "The Changing Role of Nonprofits in the Network Economy," Nonprofit and Voluntary Sector Quarterly (32:3), pp. 397-414.

Zorn, T. E., Flanagin, A. J., and Shoham, M. D. 2011. "Institutional and Noninstitutional Influences on Information and Communication Technology Adoption and Use among Nonprofit Organizations," Human Communication Research (37:1), pp. 1-33. 


\section{Acknowledgements}

The author thanks CLCNSW for allowing access to the development project for research use and the Tenants' Union of NSW for facilitating the use of resources to complete the paper. The author acknowledges the support of his family, and guidance of his supervisor Stephen Smith.

Copyright: (C) 2018 Anushke Guneratne. This is an open-access article distributed under the terms of the Creative Commons Attribution-NonCommercial 3.0 Australia License, which permits noncommercial use, distribution, and reproduction in any medium, provided the original author and ACIS are credited. 